\title{
Forest Biomass Estimation Based on Remote Sensing Method
}

\author{
Fuxiang Liu', a, $*$, Yuanyuan Zhang ${ }^{2, b}$ \\ ${ }^{1}$ Department of statistics at School of economics, Harbin University of Commerce, Heilongjiang Province, \\ PR China \\ ${ }^{2}$ College of Forestry, Northeast Forestry University, Harbin, Heilongjiang Province, PR China \\ a liufuxiang2009@163.com, bzmfys216@163.com \\ *corresponding author
}

Keywords: Forest biomass; Landsat TM data; Multiple Linear Regression; BP neutral net

\begin{abstract}
Using the Landsat 5 TM images in 2002 as source data, the paper constructed individual tree biomass models of seven principal species based on the data from field surveying and fixed Plots in Tahe and Amur forest Region in Daxiangan Mountains. The remote sensing biomass model between TM images and data from forest fixed Plots was developed by the methods of multiple linear regression and BP neutral net. The result showed that $\mathrm{R}$ in multiple linear regression model was 0.764 and the model passed the $\mathrm{F}$ test, $\mathrm{D}-\mathrm{W}$ test and multi-collinearity test. In the independent sample estimation, the neutral net model with the precision of $91.25 \%$ was significantly higher than multiple linear regression model with the precision of $81.02 \%$. Although the "black-box" neutral net model could not give the concrete analytical equation, this kind of model with high precision might be applied to estimate the forest biomass in large level forest biomass.
\end{abstract}

\section{Introduction}

Biomass has been focused widely on and developed into a new content in modern forestry, and it is the most basic quantitative characteristic of ecosystem. In forestry research, forest biomass not only shows the forests management level and the value of development and utilization of forests, but also reflects the complex relationship involved in material cycling and energy flowing between forest and environment. Therefore, the study on forest biomass is of great significance in practice as well as in theory. The most commonly used method of calculating biomass is with some factors, such as breast diameter, tree height, tree crown. But the method is relatively time-consuming, laborious and no unified standard now, even bad representative is caused by less samples ${ }^{[1]}$. Based on upscaling methods, the translation from Forest Resources Inventory data to regional scale biomass is a challenge ${ }^{[2]}$, moreover the upscaling method apply only to the regions of large enough sample density ${ }^{[3-6]}$. When high accuracy and big area biomass are desired, the traditional biomass estimation methods have their limits, so they cannot reflect the dynamic changes and ecoenvironment condition of large areas macroscopic ecological system, also cannot meet the need of reality. Spectrum Information of RS Image presents good apprehensive properties and updating, and is significantly correlated to Forest biomass ${ }^{[7]}$. RS method substitutes for traditional method. the major Data Source of Space Passive Remote Sensing are NOAA/AVHRR, Landsat/MSS, Landsat/TM, SPOT, CBERS/CCD and so on, Where NOAA/AVHRR with the advantages such as high time resolution and imaging large area are widely used in the fields of dynamic monitroing of biomass and Analysis of development trends [8], but it has low spatial resolution. While TM image has high spatial resolution and can be applied into estimate the meso-micro scale biomass in local area ${ }^{[9]}$.

Artificial Neural Networks (ANN) is a nonlinear structural engineering information processing system which is on the basis of the simulation of human brain mechanism of understanding and wisdom conducts. At present, artificial neural networks also have been widely used in eco system simulating, eco data processing and RS eco parameters obtaining and utilizing ${ }^{[10-11]}$.

In this paper, the multi- regression equation and neural network model were established based on 
TM imagery estimation of the forest biomass. 13 dependent variables were determined including environmental factors, biological factors and remote sensing. Comparing the two models, the reference is provided for forest biomass estimation based on remote sensing method.

\section{Study areas and data measurements}

The study was conducted in Tahe and Amur forest Region $\left(123^{\circ} \mathrm{E} \sim 125^{\circ} \mathrm{E}, 52^{\circ} \mathrm{N} \sim 53^{\circ} \mathrm{N}\right)$ on the North Slope of Yilehuli Mountain of Daxingan Mountains, northern Heilongjiang Province of Northeast China. This area is Low Mountains and Hills and high in the west and low in the east. The climate features is continental monsoon climate with cold winters and warm summers. The average annual temperature is $-5^{\circ} \mathrm{C}$, the average annual rainfall is $428 \mathrm{~mm}$, and Frost-free period is between $80 \mathrm{~d}$ to $100 \mathrm{~d}$. Main species are Mongolian pine (Pinus sylvestris var. mongolica), Larch (Larix gmelini), White birch (Betula platyphlla), Poplar (Populus davidiana, Populus ussuriensis), and etc.

Landsad 5 TM images from Beijing ground satellite stations are source data to reverse forest biomass of study areas. Main Parameters of TM are shown in Table 1:

Table 1 TM image parameters

\begin{tabular}{clll}
\hline Orbit number (WRS) & Time & Solar Azimuth & Solar elevation \\
$121-023$ & 20020524 & 149.9079427 & 54.7773094 \\
$121-024$ & 20020524 & 148.0050585 & 55.8124464 \\
\hline
\end{tabular}

Measurement Data: sample plot investigation was conducted in Tahe forest Region in 2007.Investigation time is August, when vegetation growth is at its most vigorous. 56 plots were investigated, every which is $0.06 \mathrm{hm} 2$. The sample plots were fixed when regional distribution, site condition and age group composition were more integration, so that samples collected can provide wide representation. Species investigated are willow (Salix raddeana), White birch (B. platyphylla), Spruce (Picea koraiensis), Mongolian pine (Pinus sylvestris var. mongolica), Larch (Larix gmelini), Mongolian oak (Quercus mongolica) and Poplar (Populus davidiana). Above-ground biomass equations for the above species were developed using these investigation data. The outline of sample trees form sample plot investigation is as tabled below.

Table 2 outline of sample trees

\begin{tabular}{ccccc}
\hline Specie & Number & DBH $(\mathrm{cm})$ & Height $(\mathrm{m})$ & W $(\mathrm{kg})$ \\
White birch & 32 & $7.1 \sim 17.2$ & $8.5 \sim 17.8$ & $12.01 \sim 118.90$ \\
Mongolian pine & 37 & $10.1 \sim 28.1$ & $8.2 \sim 16.0$ & $17.35 \sim 204.60$ \\
Larch & 36 & $8.6 \sim 22.5$ & $9.3 \sim 19.4$ & $18.64 \sim 197.49$ \\
Poplar & 36 & $9.9 \sim 25.6$ & $10.9 \sim 18.8$ & $23.72 \sim 222.89$ \\
Spruce & 36 & $9.1 \sim 27.2$ & $8.2 \sim 17.2$ & $18.90 \sim 313.43$ \\
Mongolian oak & 34 & $5.1 \sim 8.2$ & $5.8 \sim 7.2$ & $3.40 \sim 14.89$ \\
willow & 20 & $7.8 \sim 18.5$ & $9.5 \sim 18.6$ & $3.29 \sim 110.91$ \\
\hline
\end{tabular}

Note: DBH represents Breast Diameter height; W represents above-ground biomass.

The fixed sample plots: Data from continuous forest inventory in 2002, there are 60 plots, every which is $0.06 \mathrm{hm} 2$. Biomass of every sample plot was calculated as database to develop RS Biomass Model.

Table 3 outline of fixed sample plots

\begin{tabular}{cccccc}
\hline Number & DBH $(\mathrm{cm})$ & Height $(\mathrm{m})$ & Canopy density & Volum $(\mathrm{m} 3 \cdot \mathrm{hm}-2)$ & $\mathrm{W}(\mathrm{t} / \mathrm{hm} 2)$ \\
\hline 60 & $4.5 \sim 23.1$ & $4.0 \sim 23.1$ & $0.1 \sim 0.9$ & $1.2 \sim 239.4$ & $0.77 \sim 143.12$ \\
\hline
\end{tabular}

Note: DBH represents Breast Diameter height; W represents above-ground biomass.

\section{Method}

\subsection{TM images and sample plots data processing}

Using Ground Control Points to carry out TM images geometric rectification, rectification results 
show that errors are less than 0.5 pixel and satisfy the rectification accuracy. The atmospheric correction were carried out using the FLAASH Module of the ENVI processing software, drawing spectral curves (Figure 1) of the vegetation from the same spot is to judge rectification results. From spectral curves before and after rectification, the blue band was reduced remarkably after rectification and obviously lower than green band, which is due to the selectivity of atmospheric scattering, that is to say atmospheric scattering has great effect on short wave and small effect on long wave. In near-infrared bands, the vegetation reflection went up much remarkably than before FLAASH rectification. Rectification results correspond to spectral characteristics of vegetations, so it had removed atmospheric influence. Based on vector administrative boundary of study areas, TM images were spliced and clipped to acquire the image map of study areas, which is base data used to withdraw remote sensing factors. Then the image map was classified by the method of unsupervised classification and evaluated classification accuracy with 250 sample points. Classification accuracy is $80 \%$, which researches the study need. Figure 2 is the land type map of study areas rectified.

The digital elevation model (DEM) was established using the contour map of Daxingan Mountains. The vector data file of study areas were spliced and clipped to acquire the DEM images of study areas, which is base data used to extract terrain factors.

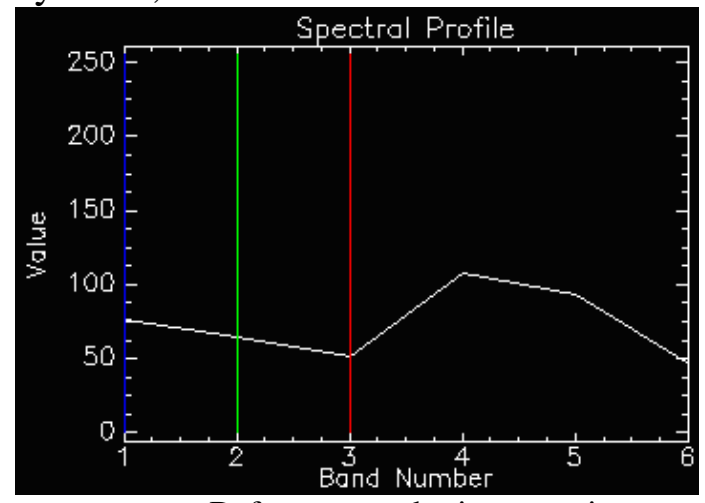

a Before atmospheric correction

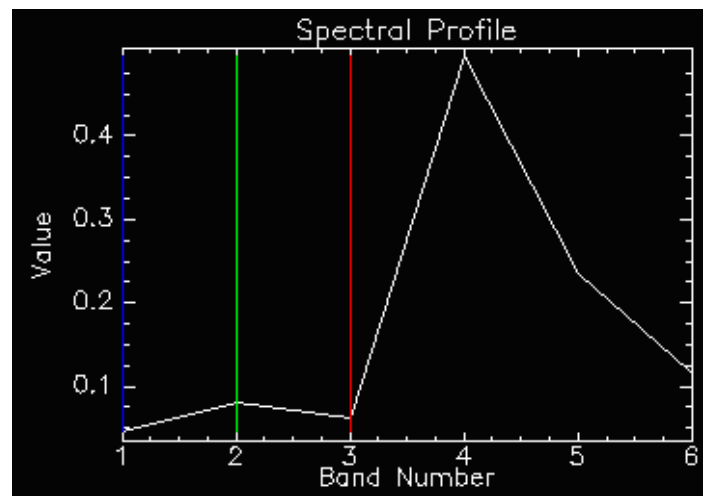

b After atmospheric correction

Figure 1 Ground Objects Spectral Reflective Curve before and after atmospheric correction
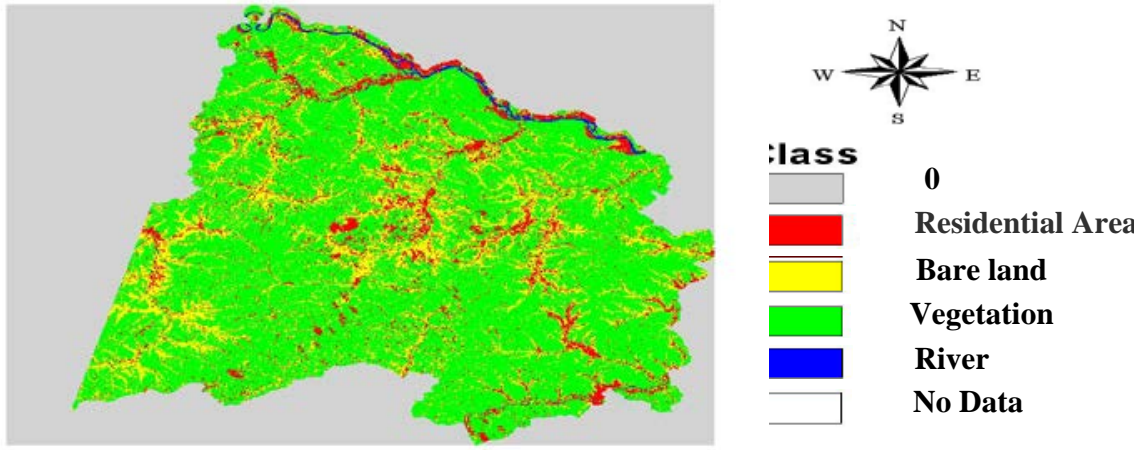

Figure 2 Tlantype map of study areas corrected

\subsection{Calculation of biomass in fixed sample plots}

TBased on measurement data of each species in 2007, seven models selected (Table 4) are used to fit individual biomass models, which were tested by using the following statistical criterions: Mean Bias (ME), and Mean Absolute Bias (MAE), Mean Percentage Error(MPE), Mean Absolute Percentage Error(MAPE), Precision(P).

Mean Error (ME): $\mathrm{ME}=\frac{1}{n} \sum_{i=1}^{n}\left(y_{i}-\hat{y}_{i}\right)$

Mean Absolute Error (MAE): MAE $=\frac{1}{n} \sum_{i=1}^{n}\left|y_{i}-\hat{y}_{i}\right|$ 
Mean Percentage Error (MPE): $M P E=\frac{1}{n} \sum_{i=1}^{n}\left(\frac{y_{i}-\hat{y}_{i}}{y_{i}}\right) \times 100 \%$

Mean Absolute Percentage Error (MAPE): $M A P E=\frac{1}{n} \sum_{i=1}^{n}\left|\frac{y_{i}-\hat{y}_{i}}{y_{i}}\right| \times 100 \%$

Precision: $P=\left(1-\frac{t_{0.05} S_{\bar{y}}}{\hat{\bar{y}}}\right) \times 100 \%$, where $S_{\bar{y}}=\sqrt{\frac{\sum\left(y_{i}-\hat{y}_{i}\right)^{2}}{n(n-p)}}$

Table 4 Models list

\begin{tabular}{ll}
\hline Number & Model \\
1 & $\mathrm{w}=\mathrm{a}(\mathrm{D} 2 \mathrm{H}) \mathrm{b}$ \\
2 & $\mathrm{w}=\mathrm{aDb}$ \\
3 & $\mathrm{w}=\mathrm{aHb}$ \\
4 & $\mathrm{w}=\mathrm{a}+\mathrm{bD} 2 \mathrm{H}$ \\
5 & $\mathrm{w}=\mathrm{aDbecD}$ \\
6 & $\mathrm{w}=\mathrm{aHbecH}$ \\
7 & $\mathrm{w}=\mathrm{aDbHc}$ \\
\hline
\end{tabular}

Note: D, H, W represents Breast Diameter Height, height, above-ground biomass, respectively; a, b, c are parameters.

\subsection{Fitting multivariate regression equation of forest biomass}

The paper extracted 20 variables to fit multivariate regression equation of forest biomass, such as terrain factors, every band of TM images, vegetation index (NDVI),Band(1 5), Band 7, ratio vegetation index (RVI), difference vegetation index (DVI), normalization vegetation index (NVI), Band (4+5-2)/(4+5+2),Band (3/7),Band (4/2), principal component PCA1, principal component PCA2, elevation, slope, aspect, Bright, Green, Wet.

\subsection{Constructing BP Neural networks model of forest biomass}

Based on MATLAB7.0, BP Neural networks model of forest biomass was developed. The structure and parameters of networks are shown in Figure 3. To compare regression models, the same variables were selected to fit models.

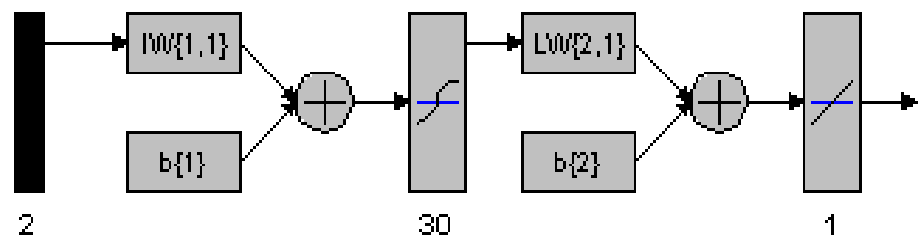

Figure 3 Structure map of BP Neural networks

Note: IW $\{1,1\}$ represents the matrix of weighted values from input layer to hidden layer; $\mathrm{b}\{1\}$ represents the threshold matrix of neuron in hidden layer; $\operatorname{LW}\{2,1\}$ represents the matrix of weighted values from hidden layer to output layer; $b\{2\}$ represents the threshold matrix of neuron in output layer.

Set network layers 3, input layer, hidden layer and output layer. The numbers of neurons in input layer, hidden layer and output layer are respectively 2, 30 and 1. the training study algorithm is trainlm, and the transfer function is tansig. Max training times of network are 500; the interval times of showing training results are 5; the error target (mean square error) is 0.005 ; training time is less than $12 \mathrm{~h}$; the mininum gradient of performance function is $10-6$, and max times of validation fails are 5. 


\subsection{Results and Discussions}

\subsubsection{Individual biomass models in study areas}

Table 5 Biomass models and parameters of every species

\begin{tabular}{clcccccc}
\hline Specie & Model & $\mathrm{R}^{2}$ & $\mathrm{ME}$ & $\mathrm{MAE}$ & $\begin{array}{c}\mathrm{MPE} \\
(\%)\end{array}$ & $\begin{array}{c}\mathrm{MAPE} \\
(\%)\end{array}$ & $\begin{array}{c}\mathrm{P} \\
(\%)\end{array}$ \\
White birch & $\mathrm{W}=0.0938 \mathrm{D}^{2.5259}$ & 0.913 & 2.983 & 8.724 & 1.58 & $\begin{array}{c}15.261 \\
87.52\end{array}$ \\
$\begin{array}{c}\text { Mongolian pine } \\
\text { Larch }\end{array}$ & $\mathrm{W}=0.002 \mathrm{D}^{4.947} \mathrm{e}^{-0.1718 \mathrm{D}}$ & 0.943 & -0.049 & 11.262 & -2.87 & -13.258 & 90.51 \\
Poplar & $\mathrm{W}=0.0133 \mathrm{D}^{3.7548} \mathrm{e}^{-0.097 \mathrm{D}}$ & 0.967 & 1.473 & 8.585 & -0.28 & 9.751 & 91.22 \\
Spruce & $\mathrm{W}=0.0032 \mathrm{D}^{4.4176} \mathrm{e}^{-0.1181 \mathrm{D}}$ & 0.946 & 0.737 & 12.97 & -1.98 & 12.805 & 88.79 \\
Mongolian oak & $\mathrm{W}=0.0085 \mathrm{D}^{3.8007} \mathrm{e}^{-0.092 \mathrm{D}}$ & 0.979 & 0.219 & 7.014 & -1.73 & 8.875 & 87.31 \\
willow & $\mathrm{W}=0.0019 \mathrm{D}^{7.5614} \mathrm{e}^{-0.855 \mathrm{D}}$ & 0.924 & 0.019 & 0.556 & -0.63 & 6.028 & 97.62 \\
\hline
\end{tabular}

\subsubsection{Multivariate regression equation of forest biomass}

The regression equation of RS is shown as:

$\mathrm{W}=-888.126-370.059 * \mathrm{PCA} 1+1276.57 * \mathrm{~B} 245$

Where $\mathrm{W}$ represents above-ground biomass (t/hm2); PCA1 is the first principle component acquired after principle component analysis for TM images; B245 represents the combination of 2,4,5 band, B245=Band (4+5-2)/ $(4+5+2)$; The result of test on the regression equation suggested the significance of multiple regression and the reliability of regression equation $(R 2=0.76, F=32.9$, $\operatorname{sig}=0$ ). $\mathrm{DW}=2.048 \approx 2$ shows that the residual of the two adjoing points is independent.

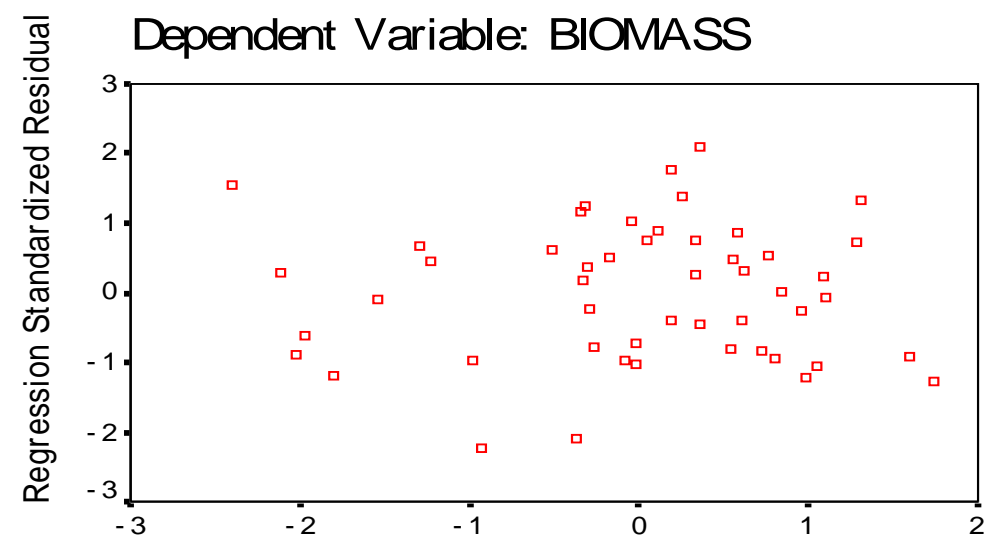

Regression Standardized Predicted Value

Figure 4 Residual scatter plot

\subsubsection{BP Neural networks model of forest biomass}

Train the Neural networks model of forest biomass developed, and the result is shown as following:

$$
\begin{aligned}
& I W\{1,1\}=\left[\begin{array}{lrrrrl}
5.2164 & -5.3745 & 5.7153 & -0.1734 & 10.7506 & \cdots-7.6699 \\
-5.5821 & 5.0869 & -6.6030 & 8.4290 & -2.7661 & \cdots 2.3629
\end{array}\right]_{2 \times 30}^{T} \\
& b\{1\}=\left[\begin{array}{lllllll}
-7.7043 & 7.5238 & -5.9922 & 5.7564 & -4.5757 & \cdots & -7.3228
\end{array}\right]_{1 \times 30}^{T} \\
& L W\{2,1\}=\left[\begin{array}{lllllll}
0.5248 & 0.0983 & 1.8594 & 2.7988 & -4.2797 & \cdots & -0.4771
\end{array}\right]_{1 \times 30} \\
& b\{2\}=[-1.1851]
\end{aligned}
$$




\subsubsection{Model test}

Using the following statistical criterions: Mean Bias (ME), and Mean Absolute Bias (MAE), Mean Percentage Error(MPE), Mean Absolute Percentage Error(MAPE), the models were tested.

Table 6 Comparing test parameters of BP Neural networks model and Multivariate regression model

\begin{tabular}{llllcc}
\hline Model & ME & MAE & MPE(\%) & MAPE(\%) & P(\%) \\
Regression model & -1020.23 & 1116.7 & -17.8 & 18.98 & 81.02 \\
BP model & -3554 & 6408 & -4.08 & 8.75 & 91.25 \\
\hline
\end{tabular}

\section{Conclusion}

The study results showed that the fitting accuracy of Multivariate regression model were satisfied, which illustrated the relationship between forest biomass and RS factors; the BP Neural networks model of forest biomass developed can attain more precise result, although the directional law cannot be generalized from the model.

The ability for Nonlinear Approach of the BP Neural networks model of forest biomass developed is satisfactory, but using the method for estimating forest biomass, there are some problems to solve, such as predictors selection is an issue. In real work, it will come up that the fitting accuracy of models is satisfied, but the extrapolation is poor. The prime cause of the trouble is whether the selection of predictors is representative.

\section{Acknowledgements}

This research was financially supported by Doctor Startup Fund of Harbin University of Commerce (14rw12), Postdoctoral Startup Fund of Harbin University of Commerce (2017BSH029), the periodical achievement of the general project of the national social science foundation (17BJY119) and Program for Philosophy and Social Science for the Planning of Heilongjiang province (16JYE01)

\section{References}

[1] Hese S, Lucht W, Schmullius C, et al. Global biomass mapping for an improved understanding of the CO2 balance_- the Earth observation mission Carbon-3D. Remote Sensing of Environment, 2005, 94: 94 104.

[2] Janssens I A, Freibauer A, Ciais P, et al. Europe's terrestrial biosphere absorbs 7 to $12 \%$ of European anthropogenic CO2 emissions. Science, 2003, 300: 1538 1542.

[3] Kauppi P E, Mielikinen K, Kuusela K. Biomass and carbon budget of European forests 19711990, Science, 1992: 256, 70 74.

[4] Liski J, Korotkov A V, Prins C F, et al. Increased carbon sink in temperate and boreal forests. Climatic Change, 2003, 61: 89 99.

[5] Nabuurs G J, Schelhaas, M J, Mohren G M J, et al. Temporal evolution of European forest sector sink from1950 to 1999.Global Change Biology, 2003,9: 152 160.

[6] Shvidenko A, Nilsson S. Dynamics of Russian Forests and the Carbon Budget in 1961-1998: An assessment based on long-term forest inventory data. Climatic Change, 2002, 55: 5 37.

[7] Spencer R D, Green M A, Blggs P H. Integrating Eucalypt Forest Inventory and GIS in Western Australia. Photogrammetric Engineering \& Remote Sensing, 1997, 63(12): 1345 1351

[8] John Thorpe. Aerial Photography and satellite. EOM, 1996,5(4):39 41

[9] Qingxi Guo, Feng Zhang. Estimation of Forest Biomass Based on Remote Sensing. Journal of Northeast Forestry University,2003,31(2):13 16

[10] Lek S, Guegan J F. Artificial neural network as a tool in ecological modeling, an introduction [J]. Ecological Modeling, 1999, 120: 65- 73. 